\title{
El lugar del centro comercial en Cali: el caso del Parque comercial Río Cauca y Unicentro*
}

\author{
Juan David Mesa** \\ (jdmesa@icesi.edu.co)
}

Artículo de investigación recibido el 16/02/2016 y aprobado el 19/05/2016.

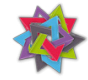

Cómo citar este artículo:

MESA, Juan David (2016). "El Lugar del centro comercial en Cali: el caso del Parque comercial Río Cauca y Unicentro”. En: Trans-pasando Fronteras, Núm. 10, pp. 97-118. Cali, Colombia: Centro de Estudios Interdisciplinarios, Jurídicos, Sociales y Humanistas (CIES), Facultad de Derecho y Ciencias Sociales, Universidad Icesi.
\end{abstract}

\section{Resumen}

A partir de los años setenta en Cali el comercio se comenzó a trasladar del centro de la ciudad a los centros comerciales. En ese sentido, las dinámicas de interacción usuario-consumo se transformaron por completo, posibilitando que los compradores pudieran encontrar "todo" en un mismo espacio. De ese modo, autores como Vásquez (2001) han catalogado estos centros comerciales como no-lugares, partiendo de un supuesto que concibe que en estos espacios no es posible la creación y estructuración de vínculos duraderos. Por todo esto, un aspecto fundamental en este artículo radica en cuestionar ese planteamiento que caracteriza a los centros comerciales como no-Lugares, proponiendo, en contraste, que se han ido diversificando y transformando de tal modo que en la actualidad se constituyen como Lugares

Este artículo se enmarca en múltiples investigaciones realizadas entre 2014 y 2015 en el marco del seminario de Sociología del diseño y el curso Estudios Regionales y Urbanos de la facultad de Derecho y Ciencias Sociales de la Universidad Icesi.

** Estudiante de Maestría en Estudios Sociales y Políticos, docente e investigador en formación, y sociólogo y profesional en mercado internacional y publicidad de la Universidad Icesi. 
en donde se construyen sujetos particulares de consumo, en este caso jóvenes: agentes de interés para el presente estudio. Para tal reflexión, será primordial analizar dos centros comerciales para contrastar las formas de apropiación espacial por parte de los jóvenes: Parque comercial río Cauca y Unicentro.

\section{Palabras clave:}

Centro comercial, Jóvenes, Lugar/No-Lugar, Parque comercial Río Cauca, Unicentro.

\section{Introducción}

Con el auge de la construcción en Cali en la llamada reconfiguración contemporánea de finales de los setenta hasta la actualidad (Almario, 2012), el comercio se comenzó a descentralizar, concentrándose en varias áreas de la ciudad alrededor del modelo occidental de negocio por excelencia: los centros comerciales. Con Unicentro, Cosmocentro y la 14 de Calima como los primeros centros de comercio de la ciudad, las dinámicas de interacción usuario-consumo se transformaron por completo, dándoles la oportunidad a los compradores de encontrar "todo" en un mismo lugar. En ese sentido, algunos investigadores han catalogado a estos centros de comercio como no-Lugares en tanto que no son espacios en donde se puedan crear vínculos duraderos entre las personas que allí transitan (Vásquez, 2001).

Mi interés, en ese sentido, radica en cuestionar dicho planteamiento que caracteriza a estos centros comerciales como no-Lugares, proponiendo, en contraste, que se han ido diversificando de tal modo que en la actualidad se constituyen como Lugares en donde se construyen sujetos particulares de consumo, en este caso en jóvenes, ${ }^{1}$ a la vez que son percibidos por los habitantes de la ciudad que los frecuentan, como puntos fundamentales para la interacción social y el ocio. Para tal reflexión, analizaré dos centros comerciales que se encuentran en zonas socioeconómicamente hablando muy diferentes de la ciudad para contrastar las formas de apropiación espacial por parte de los jóvenes: Parque comercial Río Cauca y Unicentro. La elección de este segmento de la población obedece a que, como lo mostraré más adelante, se constituye como un público objetivo ideal para las interacciones de consumo del centro comercial.

\footnotetext{
1 Específicamente, jóvenes entre los 15 y 25 años de edad.
} 
En suma, me interesa repensar los centros comerciales en Cali como escenarios fundamentales dentro del imaginario de los jóvenes, a partir del análisis comparativo de sus formas de uso y apropiación del espacio en los dos centros de comercio mencionados, en los días y horarios en donde son más frecuentados por los segmentos en cuestión: pues, además de las formas de uso, pueden variar también los horarios de apropiación. Para tal fin, surge un interrogante: ¿Cómo son las formas de uso o apropiación espacial por parte de los jóvenes en Unicentro y Parque comercial río Cauca que permitan pensar dichos centros de comercio como Lugares? Posiblemente, como lo venía diciendo, esas dinámicas de apropiación varían de acuerdo el sector en donde se encuentran los centros de comercio y también pueden variar según la hora y el día: aspectos que, por supuesto, fueron tenidos en consideración en este proceso de indagación.

Para responder a dicho interrogante, propongo una reflexión teórica, descriptiva y etnográfica ${ }^{2}$ en donde el lector se podrá encontrar, como producto de esta indagación, los siguientes apartados. Primero, una contextualización histórica del centro comercial como concepto desde un abordaje teórico y como concepto situado en Cali de la forma como lo estoy entendiendo: precisamenete, como Lugar. Segundo, el análisis de las formas de apropiación por parte de los jóvenes y la reflexión acerca de la incidencia del contexto como determinante o no de dicha dinámica introduciendo los casos particulares de Unicentro y Centro comercial río Cauca. Finalmente, las conclusiones.

\section{El Lugar y el centro comercial}

\section{La dualidad Lugar-No-Lugar}

Las propuestas sobre la conceptualización del Lugar como categoría urbana de análisis son variadas y disciplinarmente diversas. Según Antonio Castrogiovanni, "el Lugar es una porción de espacio apropiable para la vida; es vivido, reconocido y posee identidad. Tiene densidad técnica, comunicacional, informativa, normativa, simbólica y turística" (2007: 16). Para este autor, el Lugar vendría a ser, en esencia, un producto de la interacción humana que se produce y reproduce en la correspondencia entre el espacio y la sociedad, en relación con lo particular y lo colectivo: relación que establecería las bases para la

2 Como complemento a la observación en trabajo de campo se entrevistaron cuatro jóvenes en cada centro comercial: dos hombres y dos mujeres en cada caso. 
creación de una identidad propia de la comunidad del Lugar. Por todo esto, se despliega el hecho de que un espacio es un Lugar en tanto se construye a partir de relaciones sociales, a la vez que da sentido a la configuración de una identidad que permita el desarrollo de dichos vínculos.

Sin embargo, para entender la acepción de Lugar, es importante entender su dimensión contraria: el No-Lugar. Para Castrogiovanni:

\begin{abstract}
El No-Lugar se diferencia del Lugar no sólo por su forma en su proceso de constitución. Ambos son fruto de construcciones sociales, mientras que el NoLugar está hecho a medida de la época (...) el No-Lugar es por lo tanto la ausencia del Lugar en símismo. La lógica del No-Lugar responde a que los sujetos no se detienen (Castrogiovanni, 2007: 19).
\end{abstract}

En ese sentido, el No-Lugar pareciera ser la simple negación del Lugar. El Lugar y el No-Lugar serían polos opuestos de una dualidad inseparable: el primero no se acaba completamente y el segundo nunca se realiza totalmente. Así mismo, no habría que dejar de lado que la lógica discursiva del No-Lugar obedezca a la necesidad de los sujetos, en ciertos ámbitos, de no detenerse: acepción que se refiere a la "no-necesidad" de construir relaciones en ciertos ámbitos, punto importante en este escrito para la discusión más adelante.

Para Campos y Yávar, por otro lado, “el Lugar surge cuando es articulado, cuando las relaciones que estaban latentes en el espacio son actualizadas por las personas" (2007: 44): en pocas palabras, cuando son re-significadas. Este planteamiento se fundamenta en el reconocimiento de dos dimensiones para referir al Lugar: "primero, una visión temporal que permite la realización de los contenidos latentes que se encuentran en el espacio y, segundo, las prácticas humanas que son las que efectivamente realizan los contenidos posibles" (2007: 45).

Esta propuesta se asemeja a la de Castrogiovanni (2007) en tanto que condiciona la caracterización de un espacio como Lugar, siempre y cuando esté cargado simbólicamente de un discurso que dé sentido a lo que se hace dentro de sus dimensiones como entorno, y siempre y cuando las relaciones que ahí se tejen sean consecuentes con ese discurso. De este modo, el Lugar pasa a constituirse en una relación dada "entre espacio y conducta en 
una temporalidad concreta. La 'Iugarización' remitiría así a un proceso de diferenciación del territorio que efectúa un sistema previamente constituido, ya que el espacio por sí solo no genera sistemas sociales" (Campos y Yávar, 2007: 52).

En síntesis, un espacio se configura como Lugar porque materializa una estrategia discursiva que planea decretar el tipo de relaciones que se deben presentar por parte de los sujetos que interactúan en dicho entorno: el Lugar, pues, es un espacio pensado, premeditado y construido intencionalmente. Este factor que demarca al Lugar como un plan estratégico, deja pensar en una dinámica de control y vigilancia alrededor de la cual se configura dicha intencionalidad. Así, por ejemplo, una institución educativa, que ha sido pensada en clave de ciertas normas, circunscribe un proceso de control espacial sobre los sujetos que allí se relacionan, por pensar un escenario foucaultiano.

Hay que dejar claro que ese control, desde la mirada de Foucault, se presenta como un dispositivo de poder sobre los cuerpos de los implicados en la relación con el Lugar directamente: relación que el autor definiría con el concepto de heterotopías. Así, pues, Foucault hablaría de espacios heterotópicos al referirse a aquellos espacios de interacción y, sobre todo, de control y vigilancia. En sus palabras, las heterotopías se podrían definir como "un lugar real en el que se yuxtaponen diferentes espacios incompatibles" y en donde el resultado es una dinámica biopolítica de control sobre los cuerpos que ahí interactúan (Foucault, 1998: 29).

Sin embargo, la acepción teórica de heterotopías en Foucault (1998) no tiene en consideración las dinámicas de consumo en la sociedad de hoy. Sobre este punto, Preciado (2010), partiendo de la anterior noción, se refiere a espacios pornotópicos como la categoría más colindante para explicar las dinámicas de consumo del sistema capitalista moderno al que llama capitalismo farmacopornográfico haciendo alusión a la dimensión del espectáculo en esa lógica económica. Para la autora, “el capitalismo farmacopornográfico podría definirse como un nuevo régimen de control del cuerpo y de producción de la subjetividad" (Preciado, 2010: 113).

Así mismo, sostiene que "lo que caracteriza a la pornotopía es su capacidad de establecer relaciones singulares entre espacio, sexualidad, placer y tecnología (audiovisual, bioquímica, etc.), alterando las convenciones sexuales o de género y produciendo la subjetividad sexual como un derivado de sus operaciones espaciales" (Preciado, 
2010: 120). La pornotopía, en suma, viene siendo un Lugar que tiene injerencia sobre los sujetos a través de una serie de procesos donde media el placer y el control sobre los cuerpos sexuados.

De lo anterior se pueden resumir tres puntos fundamentales a propósito de la conceptualización de la categoría de Lugar. Primero, es relevante reflexionar alrededor del Lugar como un espacio que es pensado intencionalmente a partir de un discurso cargado simbólicamente que da sentido a las relaciones sociales que allí se tejen como respuesta a esa configuración premeditada. De ahí que el segundo punto determinante para entender la concepción de Lugar, sea precisamente a partir del dualismo con su opuesto teórico: el No-Lugar. Esta negación del Lugar responde a una lógica de espacio en la que "los sujetos no se detienen" precisamente porque al no ser planeado, no da sentido y, por ende, no funda relaciones sociales o si las funda, éstas se constituirían como lazos llanamente efímeros: aunque al igual que los Lugares, los No-Lugares también son planeados precisamente con ese fin de hacer "pasar" y no de hacer "quedar". Así, el tercer punto a considerar es que como espacios planeados, los Lugares operan bajo una lógica de control en donde el discurso simbólico funciona como dispositivo para la construcción de sujetos ideales a partir de la vigilancia sobre sus cuerpos: razón por la cual, deben considerarse en algunos casos como heterotopías, si la meta intencional es la disciplina, o espacios pornotópicos, si la meta intencional son cuerpos sexuados mediados por la relación entre placer y espectáculo en el llamado capitalismo consumista tardío.

Centro comercial: ¿Lugar o No-Lugar?

Teniendo en cuenta los elementos anteriores, para el caso de estudio del presente trabajo, ¿se constituyen el parque comercial Río Cauca y Unicentro como Lugares? Para responder a esta pregunta considero importante responder primero a la pregunta (teórica) de qué es un centro comercial, para luego pasar a analizar el caso particular de cada uno de estos casos en el contexto de Cali.

Para los años sesenta y como preocupación ante las transformaciones de una sociedad tradicional a una del espectáculo, Guy Debord haría la siguiente reflexión refiriéndose a ese desconocido espacio que emergía como nueva apuesta urbanística: "la gente trabaja seis días de la semana para gastarse todo el séptimo día. En estos tiempos en que el di- 
nero es un dios, el centro comercial en verdad parece ser su templo" (Debord, 2003: 90). Haciendo alusión a una paradójica analogía, Debord expresa la forma como el centro comercial comenzó a ocupar la cotidianidad de las personas, convirtiéndose en un espacio fundamental para la interacción social y el entretenimiento.

En esa medida, el centro comercial como un espacio de la ciudad para ir y ser apropiado, se comenzó a configurar gracias a la incursión de este modelo de negocio en los Estados Unidos hacia los años cuarenta. Según Chacón (2010), pensando en los inicios de este nuevo espacio en el país del norte, la noción que "mejor expresa el origen y posterior desarrollo de la idea de centros comerciales se refiere a un espacio configurado a manera de pasillo amplio o calle interior, bordeada por sus dos costados por locales comerciales de diversos tipos de productos", siempre en un entorno controlado y resguardado del exterior, es decir, cubierto, climatizado y, por supuesto, vigilado (Chacón, 2010: 94).

Posteriormente, hacia la década de los cincuenta, se fueron implementando innovaciones tecnológicas como la climatización artificial, las escaleras mecánicas y los sitios de parqueo como respuesta a la necesidad incipiente de seguridad. Para este autor, "la más reciente incorporación de los centros comerciales es la elaboración de 'entornos atractivos' mediante la manipulación de todo lo perceptible por los sentidos del 'cliente', el olor, la luz, el aire, las texturas y los sonidos" (Chacón, 2010: 96). El elemento fundamental de estos entornos, diría, es la artificialización del entorno natural que se transforma en uno de los principales medios para cautivar al consumidor, mientras ofrece un ambiente familiar garantizando el 'éxtasis comercial', representado en mayores niveles de consumo.

Por su parte, Molinillo (2002) define el centro comercial como una dinámica de asociacionismo entre diferentes lógicas de comercio. Según este autor:

Las actuales condiciones de mercado, tanto por el lado de la oferta como de la demanda, obligan a considerar el asociacionismo como una estrategia necesaria para el comerciante tradicional, si quiere ofrecer todos aquellos servicios que el mercado valora y contrarrestar la atracción de otras formas comerciales periféricas y de ese modo prosperar económicamente (Molinillo, 2002: 165).

Además de ser un espacio en donde convergen distintos tipos de interacciones mediadas por la variedad en la oferta, un punto significativo para entender la importancia del centro 
comercial en las dinámicas urbanísticas de la ciudad es que al ser un espacio planeado, determina el entorno urbano que lo rodea. Al respecto nos dice Chacón que "los centros comerciales son protagónicos para la planificación y construcción de la ciudad, pues se constituyen como referentes urbanos determinantes, especialmente en lo concerniente a sus dinámicas internas y externas" (2010: 97).

Por esa misma vía, Medina plantea que "con el centro comercial estamos dando el paso de la ciudad tradicional, de la ciudad centralizada, a un ciudad fragmentada y dispersa, y a una nueva manera del habitante de las ciudades para relacionarse con lo público" (1998: 62). El centro comercial sería una expresión de los procesos de exclusión urbanos y de la privatización de los espacios públicos al ser ejemplo de la nueva monumentalidad urbana y signo de modernización.

De todos modos, esta "Burbuja de cristal" trasgrede los lineamientos tradicionales urbanísticos al ser un espacio encerrado sobre sí mismo que no corresponde a la idea de "la calle urbana, ni a su fluir, ni a la concentración vital y social de la plaza por su alejamiento de la trama y del centro de la ciudad" (Medina, 1998: 64). Pareciera como si los centros comerciales hubieran surgido cuando el protagonismo económico, cultural y político del centro de la ciudad se terminó, perdiendo relevancia el área central de la urbe, haciendo que "el éxodo de los habitantes hacia áreas suburbanas aumente, y el morador de las ciudades pierda el sentimiento de vida en comunidad" (Medina, 1998: 64).

Recogiendo todas estas posiciones es importante agregar que el centro comercial aparece como un espacio de la ciudad para ir y ser apropiado, con elementos objetuales que lo conforman en tanto innovaciones tecnológicas como la climatización artificial, las escaleras mecánicas y los sitios de parqueo. Esa burbuja de cristal se conforma en una dinámica de asociacionismo de diferentes tipos de oferta comercial que incentivan diversos tipos de interacciones y hábitos de consumo por parte de los usuarios. Así mismo, el centro comercial, que trasgrede la idea tradicional de urbanidad por su conformación cerrada, pareciera ser el resultado de la pérdida de protagonismo político, económico y cultural de los centros de las ciudades, provocando una suerte de fragmentación urbana.

Para efectos del presente trabajo, además de la conceptualización anterior, entenderé centro comercial como un espacio privado grande, semicerrado, con zonas verdes al aire libre y otras "al aire acondicionado", con múltiples ofertas comerciales para distintos tipos 
de usuarios y con una dinámica de control mediada por el dispositivo de la vigilancia contratada. De ahí que, partiendo de este "tipo ideal", espacios en Cali como Cosmocentro, la 14 de Calima, Chipichape, Palmetto, Unicentro y el Parque comercial Río Cauca entren, por lo menos de forma parcial, en la categoría en cuestión.

\section{El caso del Parque comercial Río Cauca y Unicentro}

La llegada de la lógica del centro comercial a Cali

Durante la primera mitad del siglo XX Cali comenzó a ser el epicentro de las decisiones administrativas, políticas y económicas del naciente departamento del Valle en 1910 y más adelante del suroccidente colombiano. Este proceso en el que existió un acérrimo afán por consolidar a la ciudad alrededor de un entorno moderno, lo denominaría Oscar Almario como la configuración moderna de Cali como ciudad-región. Hasta mediados de los cincuenta, donde se podría ubicar este periodo, es relevante mencionar el proceso de ruptura con el pasado colonial, la consolidación de las redes de conexión con el sur y el norte del país a partir de carreteras y el ferrocarril del pacífico, y la consolidación de un modelo de productividad que posicionó a Cali como una de las ciudades más importantes de Colombia (Almario, 2012).

Así mismo, este autor menciona un segundo proceso entre 1960 y la actualidad, que tendría que ver con la reconfiguración contemporánea de la región y de la ciudad-región. Este proceso se caracterizaría por la re-significación y el agotamiento del modelo desarrollista de productividad y por la función de la globalización y los mercados mundiales en las decisiones municipales y regionales que en el Valle del Cauca y Cali serían notoriamente fundamentales. Dentro de las dinámicas más relevantes, cabe mencionar las oleadas migratorias que arribaron a la capital del departamento del Valle que aumentaron exponencialmente la población de la ciudad, la desconcentración poblacional a raíz de lo anterior y la creación de múltiples ejes urbanos a partir de invasiones en zonas periféricas de la ciudad, en oriente y la ladera, que crearían un circulo de pobreza sumamente latente alrededor de procesos de exclusión y marginalidad (Almario, 2012).

Pero, sin duda alguna, un proceso que sería determinante para la configuración urbana actual de la ciudad fue la transformación de un entorno concéntrico a uno disperso, fragmentado y disgregado por toda el área urbana. El centro de la ciudad, pues, comenzó 
a perder protagonismo, sobre todo en lo concerniente a la comercialización de bienes y servicios: la ciudad se comenzó a pensar hacia el sur y el norte, y se comenzó a poblar conflictivamente hacia el oriente y la ladera, haciendo que ya no todo girara en torno al centro sino a concentraciones propias de cada sector.

En ese sentido, un acontecimiento importante que cambió la forma como se construía la ciudad se confirguró a partir de los juegos panamericanos del 71 celebrados por primera vez en una ciudad de Colombia. Cuando se le informó a la ciudadanía que Cali había sido escogida sede de los juegos, de inmediato se pusieron en marcha varios planes para "ordenar" la ciudad alrededor de ciertos puntos específicos para recibir con una imagen positiva y moderna el magno evento. Al respecto, se expidieron varios decretos que obligaban a las personas que residían en las inmediaciones de las futuras instalaciones deportivas a arreglar las fachadas de sus casas de un modo particular que la misma norma exigía: todo con el fin de dar una imagen de modernidad y progreso (Vásquez, 2001).

Así que, gracias también a los famosos juegos, por las construcciones en diversos espacios, Cali dejó de ser una ciudad concéntrica. De ese modo, la lógica de comercialización se fundó en otros modelos de negocio que se establecieron alrededor de un discurso de la seguridad que se legitimaba por la creciente violencia en la ciudad: por un lado, por las crecientes invasiones que generaban inseguridad en los habitantes 'pudientes' y por otro lado, por la influencia del narcotráfico que provocó incertidumbre en los caleños a raíz de la guerra entre carteles. Bajo ese contexto, diría Vásquez:

\begin{abstract}
Los espacios públicos de 'estar', que fueron sedes del encuentro, del diálogo y las relaciones estables, ceden ante los espacios de 'pasar' donde predominan la circulación, los contactos efimeros, las convocaciones masivas despersonalizadas y la observación rápida de señales que tienen la función de orientar y facilitar los flujos (Vásquez, 2001: 308).
\end{abstract}

Para Vásquez, esos espacios para 'estar' (Lugares) dieron paso a entornos urbanos pensados desde un discurso de seguridad que legitimó la arquitectura cerrada y vigilada (No-Lugares) como por ejemplo, en su consideración, centros comerciales. En palabras del autor, en los 'Lugares' donde se tejen relaciones, se crea identidad y “se anida la historia, cada vez más abren paso a los 'no-Lugares' donde predominan, más bien, las señales, 
la información rápida, los contactos efímeros como es el caso de las autopistas (...) los gimnasios, los hipermercados, los aeropuertos y demás” (Vásquez, 2001: 308). ¿Será realmente así en el caso de los centros comerciales en Cali desde la definición planteada más arriba? Siguiendo con Vásquez:

El mall (refiriéndose a centros comerciales), más que ubicarse en busca del demandante, lo atrae. El auto, la zona de parqueo en el interior y la seguridad invitan al comparador y usuario a desplazarse (...) la fascinación depende de las características del diseño, adecuado a los deseos de la gente: zonas de parque cerradas y vigiladas que le garantizan al usuario una permanencia tranquila y prolongada (Vásquez, 2001: 306).

Siendo esto cierto, no concuerdo con Vásquez en denominar a los centros comerciales como No-Lugares en tanto que estos espacios fueron y siguen siendo planeados intencionalmente para la consecución de un tipo específico de relaciones sociales. Es cierto que la ciudad sí ha privilegiado la construcción de espacios para "hacer pasar y transitar" con ese afán modernizador y por el proceso globalizador, y que estos entornos también obedecen a un proceso de planeación. Sin embargo, las transformaciones que ha vivenciado el formato de centro comercial, como lo relaté más arriba, dan cuenta de la vívida posibilidad para pensarlos como Lugares en donde intervienen diversas interacciones sociales entre múltiples usuarios en distintas circunstancias: en suma, Lugares en donde se ha posibilitado la producción y re-producción del relacionamiento social.

De todos modos, hay que tener presente que la noción de Lugar puede ser re-considerada de acuerdo a los usos que efectivamente dan los usuarios que ahí interactúan. No siempre los usuarios actúan con base en la forma como se planeó intencionalmente; los usos y apropiaciones son constantemente trasgredidas y re-significadas: los usuarios son también agentes. Esta premisa parte de la idea de que los centros comerciales, como un todo, no son pensados masivamente, en tanto que no todos los usuarios tienen por qué encontrar necesariamente en él, el entorno ideal para relacionarse: lo que lleva a pensar que estos Lugares tienden a enfocarse en segmentos de mercados, ciertos públicos de consumo ligados a su contexto inmediato.

También puede darse el caso de que en el mismo centro comercial haya Lugares para cierto tipo de público o No-Lugares en general, como la zona de parqueo o las vías de 
acceso y salida. En ese sentido, habría que analizar si tanto el Parque comercial Río Cauca como Unicentro se pueden considerar como centros comerciales y, por ende, Lugares, privilegiando la reflexión alrededor de las formas de apropiación de los jóvenes como uno de los segmentos de mercado más atractivos para tal fin. Cabe agregar que la dinámica de apropiación se da cuando las personas que ocupan un espacio encuentran sentido a su interacción en ese entorno, lo re-significan y lo vuelven parte de su relato: posibilitando así la formación de vínculos con otros usuarios o con diversas materialidades.

\section{En búsqueda de la diversión: PC Río Cauca, Unicentro y los jóvenes}

El recorrido etnográfico empezó en el oriente de Cali en donde, hacia las cinco de la tarde de un sábado, fui arribando a ese espacio un poco desconocido para mí: el Parque comercial Río Cauca. ${ }^{3}$ Pensado en mis experiencias pasadas en contraste con las visitas que realicé, recordé que con anterioridad ya había visitado ese espacio, pero realmente no supe qué era lo que había deliberado en ese entonces respecto a él. Caminado un poco rápido para evitar la persecución de un grupo de vendedores informales, entré a lo que ese momento consideré a partir de otra tipología de espacio, menos en la de "centro comercial". Poco después, me percaté que claramente las lógicas de comercialización en ese sector eran profundamente diferentes a las percibidas por mí en espacios como Unicentro o cualquier otro centro comercial de la ciudad. Así que de inmediato comencé a notar un factor determinante que da sentido a la forma como es apropiado por los jóvenes: su desolador aspecto.

El 70\% de los locales estaban totalmente vacíos, sin comercio, sin personas, sin cosas que vender. Al caminar por los desolados pasillos, entre las escaleras eléctricas estáticas o tapadas, no fue fácil encontrar jóvenes entre las edades que me había planteado (entre 15 y 25 años) y que respondieran a esa tipología ideal de la definición. Al buscar la historia de este espacio comercial me topé con que desde 2001 se había planteado la construcción de un parque comercial en el oriente de Cali, en donde la Administración Municipal iba a tener una participación del $20 \%$ del presupuesto y los inversionistas privados el restante $80 \%$. El proyecto fue autorizado por el Concejo con una inversión aproximada a $\$ 7.000$ millones para un lote de 71.560 metros cuadrados propiedad del municipio. El nombre

3 En total realicé tres visitas en días y horarios distintos: en este orden, sábado en la tarde noche; miércoles en la tarde; y viernes en la tarde noche. Aplicaron las mismas condiciones en el caso de Unicentro. 
original de la sociedad es "Complejo Comercial Desepaz Galería de Oriente", localizado efectivamente en esa parte de la ciudad (Uribe, 2012). Sin embargo, este complejo se conoce popularmente como "Parque Comercial Río Cauca" inaugurado en 2009: pero claramente, hoy al 2016, todavía sin terminar y prácticamente abandonado.

Sin ahondar mucho sobre las razones de tal abandono, fue pasando el tiempo, el cielo se fue oscureciendo y el gran espacio que ocupaba la entrada reflejaba el desolador panorama de un sitio que, hasta ese momento, solo estaba siendo apropiado por algunas familias con sus hijos, algunos adultos mayores bebiendo cerveza y uno que otro trabajador de los locales dando un paseo.

Fue así como de a poco me fui percatando de la tímida presencia de algunos jóvenes que me permitieron ingresar por un momento en su cotidianidad en ese espacio, explicándome sus motivaciones y razones de estar ahí. ${ }^{4}$ El primero de ellos fue Andrés, que aparentemente estaba a la espera de alguien en el momento en que le hablé. En ese momento, este joven conversaba con alguien por celular, miraba afanoso a todos los lados y me dejó saber que "más tardecito se iba a tomar algo por ahí" haciendo referencia al Parque comercial.

Ya hablando con Natalia, joven usuaria del Parque de 20 años que entrevisté, pude percatarme de varios aspectos fundamentales para la caracterización de este espacio. Natalia reside en el distrito de Aguablanca, más particularmente en el barrio Alfonso Bonilla Aragón en la comuna 14. En sus palabras: "la primera vez que fui al Parque comercial fue en 2010, cuando tenía 17 años”. Sus principales motivaciones para ir, tenían que ver con el hecho de que éste era el primer centro comercial en el oriente de Cali, lo que ofrecía una experiencia diferente para este sector y porque, además, sus amigos iban regularmente, provocándole mucha curiosidad.

Según contaba, “en el distrito no había lugares para estar entre amigos: los parques solían y suelen estar abandonados, son inseguros por las pandillas, desorganizados y poco atractivos. En el parque comercial vimos un espacio para pasarla bien sin necesidad de salir de donde vivíamos". Carlos pensaba algo similiar cuando expresaba cómo en un principio ir al Parque comercial era una forma de escapar a esa cotidianidad violenta de su barrio, en 
su caso, el Desepaz: "uno pensaba que al ser algo así cerrado iba a ser seguro, no como los barrios en donde es un peligro salir así usted sea de ahí". Estos fragmentos del relato de estos usuarios sumado a la observación los días de campo me permitieron entender una forma importante de apropiación por parte de los jóvenes: estos jóvenes que suelen ir al Parque comercial Río Cauca (cada vez menos), trasladan las dinámicas barriales a este espacio sin la necesidad de salir de sus comunas hacia sectores en el sur o norte de la ciudad. El Parque comercial era un espacio en donde se podía vivir el barrio sin la incidencia (tan explícita) de la violencia y la incertidumbre: aunque con el paso de los años se comenzaron a trasladar también "situaciones indeseables", en palabras de Andrés.

María es contundente con su relato en ese sentido: “es que por acá a uno le gusta estar por ahí con los amigos, así sea en el piso afuera de las casas o en el parque (...) aquí en el barrio uno se contenta, el problema es que hay mucha calentura y por eso uno a veces evita salir". Ante la imposibilidad de "salir" al barrio, ir a los parques, estar seguros y poder pasar un momento agradable, los jóvenes que viven a los alrededores, ven el Parque comercial como un espacio apto para realizar eso que afuera de sus casas no pueden o on se sienten seguros de hacer. Al trasladar las lógicas del barrio, este espacio comercial se convierte en parque, plaza, calle, bar, estanco, cancha de fútbol, un lugar para caminar o simplemente un Lugar para “estar seguros” y disfrutar, como dirían estos jóvenes.

Para Cornejo, 'estar' en un centro comercial es una manera de hacer y practicar la ciudad (...) "Conjeturo que los fragmentos del espacio urbano no son unidades pasivas e inamovibles, sino más bien en ellos tienen espacio diversos movimientos culturales, donde el entorno físico y la práctica simbólica se mixturan para trastocarlos en lugares habitados" (2006: 14). El Parque comercial, en este caso, es una manera de hacer y practicar el barrio que para estos jóvenes, ante los diversos procesos de exclusión, es su ciudad pues al fin y al cabo lo ven como un espacio "para pasarla bien sin necesidad de salir" de su área de interacción barrial:

En otras palabras, asistir a un centro comercial forma parte de los derroteros cotidianos -configurados por una serie de lugares a los que concurrimos por diversas razones-, a través de los cuales habitamos y hacemos nuestra una de las ciudades más grandes del mundo (Cornejo, 2006: 15). 
Así, pues, la forma de "vivir la ciudad" que más preferían estos jóvenes cuando iban más seguido al Parque comercial era "ir a hablar a los bares e ir al cine cuando fue inaugurado" y sentarse por lo juegos mecánicos, ya que alrededor de ese espacio había mucho para hacer: comer helado, tomar cerveza, hablar, las zonas verdes. En pocas palabras, 'estar' en espacios propicios para hablar y compartir con su grupo de amigos: asociación de usuarios muy común en lo que pude observar. Sin embargo, algo pasó con el Parque comercial. Ya nada sería igual. Además del abandono de los locales, muy pocas personas suelen transitar por el espacio: durante mi estadía en trabajo de campo, incluso en "horas pico de comercio”, la afluencia de público era mínima. De hecho, muchos de los jóvenes entrevistados iban a pasar un rato a solas, pues "a muchos ya no les gusta este lugar" como diría Carlos sentado solo tomando cerveza. Para Natalia:

\begin{abstract}
Antes el parque era una linda oportunidad para hablar con los amigos, para establecer relaciones y para disfrutar. Todos los fines de semana no le cabia un alma porque hacian conciertos o simplemente porque armaban las rumbas allá. Ahora, eso mantiene solo, ya casi nadie va.
\end{abstract}

¿Será entonces este Parque comercial un Lugar para los jóvenes? De acuerdo a la conceptualización que daba anteriormente, este espacio no se constituiría per se como un centro comercial: por el simple hecho de estar abandonado y de recibir a tan poca gente, no hay una dinámica abierta y diversamente comercial que lo constituya como tal. De hecho su nombre de "Parque", así no sea con ese propósito explicito, deja ver una intencionalidad de acercarse al formato de centro comercial, sin alejarse de formatos más tradicionales como un "sanandresito" o una galería, tal vez como estrategias para llegar a los públicos "populares" de sus alrededores: haciendo que se perciba más bien, desde el plano de lo urbano, como una hibridación de formato comercial. En palabras de María: "Yo creo que ese lugar nunca se llegó a constituir como centro comercial, nunca lo fue y no creo que llegue a serlo".

Cuando las dinámicas indeseables del barrio también se trasladaron a este espacio por el abandono, la inseguridad y la desorganización, estos jóvenes perdieron la motivación y no siguieron yendo con la misma frecuencia. Todo eso ha generado que los espacios de apropiación se limiten a aquellos que sí brindan la satisfacción de necesidades de seguridad y comodidad, como es el caso del cine y los pocos locales de comida rápida. Sin embargo, 
no por esto el Parque comercial Río Cauca deja de ser un Lugar para los jóvenes, pues se siguen presentando interacciones sociales, formas de apropiación y re-apropiación ante la trasformación del espacio. Tal vez llegue el día en que los jóvenes no le encuentren sentido, haciendo que se convierte en un No-Lugar más para ir de paso a pagar el recibo de los servicios y quién sabe qué otro tipo de "vuelta" más.

Con Unicentro ocurre lo contrario. Ni la aberrante publicidad, ni la cantidad de gente impiden que los jóvenes se motiven para ir de forma constante a este espacio del sur de Cali. Mirando la dinámica años atrás, es clave dar cuenta de cómo con el fin de descentralizar Unicentro y Multicentro (unidad residencial adyacente al centro comercial), se inició en 1978 en Cali la construcción de un complejo comercial y residencial similares a los de Bogotá. Unicentro Cali y Multicentro Cali fueron inaugurados en 1980 y 1981, respectivamente. Actualmente, tiene un área total de más de 137,200 m2 y más $100.000 \mathrm{~m} 2$ construidos de los cuales $65.000 \mathrm{~m} 2$ corresponden al área comercial. Así mismo, cuenta con más de 390 locales comerciales, 182 oficinas y 2800 parqueaderos (Unicentro, 2015).

Hablando al respecto con Juan, joven usuario de Unicentro de 21 años que entrevisté, pude observar que la dinámica de apropiación del espacio obedece a lógicas muy diferentes a las que se presentan en el Parque comercial Río Cauca. La motivación de Juan subyace en la cercanía que hay entre su casa y Unicentro: Juan vive en las Quintas de don Simón ${ }^{5}$ y, a diferencia de los jóvenes del oriente, apela a ir a este espacio como una forma de cambiar su cotidianidad, pues ir al parque, caminar o hablar con los amigos en la calle no le gusta. Juan, pues, no va en búsqueda de trasladar las dinámicas barriales al espacio comercial.

Para Antonio, que generalmente va con amigos a cine y a comer o con su familia a hacer el mercado de la semana, Unicentro representa un espacio de distracción y tranquilidad en donde puede encontrar todo lo que necesita. Según Muller (2004), pensando en el Lugar del centro comercial en Colombia:

Éste representa un concepto urbanístico que sirve para el abastecimiento de la población con mercancía de uso a corto, mediano y largo plazo, para la satisfacción de funciones centrales de servicio, para la provisión de empleos

5 Aproximadamente a 5 minutos en carro y 15 minutos caminando. 
para una gran cantidad de personas, como lugar de esparcimiento y como foco sociocultural y comunicativo (Muller, 2004: 10).

Pero no solo en Juan y Antonio fue perceptible tal noción. Al hablar con otros jóvenes como Marcela y Paola, pude notar que Unicentro, a pesar de estar siendo remodelado constantemente, es el espacio que les permite romper con esa "rutina semanal de ir a estudiar" y luego a su casa tener que llegar. Para Marcela es clave ir a Unicentro a hablar o comer, para poder "desatrasarse" de todo lo que le tienen que contar sus amigos: "a veces en el colegio o en la casa uno no puede hablar bien cierto tipo de cosas entonces nos vemos allá y charlamos relajadas". Paola, por su parte, concibe como fundamental la multiplicidad de espacios que ofrece Unicentro para actividades más "tranquilas" como la lectura: "vengo a la librería o a tomar un café, a veces sola o acompañada, lo importante para mí es la tranquilidad que encuentro en ciertos espacios (...) es seguro, uno esto no lo puede hacer en un parque, lamentablemente".

Grupos de amigos, de amigas, parejas, jóvenes con sus familias, comiendo, tomando, hablando, jugando, caminando, leyendo, y comprando se reúnen en un mismo ambiente, en diversos espacios para departir, compartir e interactuar. Podría decir entonces que los jóvenes que van a Unicentro, no estando interesados en interactuar socialmente en espacios más ligados a la dinámica barrial (por inseguridad, por ejemplo), buscan romper con su rutina, encontrando en este espacio el Lugar perfecto para 'estar' con otras personas: el discurso de la seguridad, pues, se da por sentado.

Pareciera como si en este contexto fuera más certero hablar del adagio de Debord (2003), que me permito repetir a continuación: "La gente trabaja seis días de la semana para gastarse todo el séptimo día. En estos tiempos en que el dinero es un dios, el centro comercial en verdad parece ser su templo" (Debord, 2003: 90). Aunque en este caso sería más bien el que los jóvenes ahorren toda la semana, ansiando la llegada del "séptimo" día para romper con lo aburrido de sus cotidianidades: lo que me deja pensar que al igual que en el caso de los jóvenes en el Parque comercial Río Cauca, las formas de apropiación de los de Unicentro obedecen al contexto urbano inmediato de quienes lo usan.

Para Guerrero (2014a y 2016) Unicentro se dirige a un segmento de la población que tiende a percibir el precio como algo significante que está unido a los valores que caracte- 
rizan los consumos. Unicentro, al estar ubicado al sur de la ciudad, en una zona residencialcomercial ligada a estratos altos de la población, "se semiotiza como sitio de encuentro y de compras en un ambiente distinguido, sofisticado y elegante" (Guerrero, 2014a: 22).

Con respecto a la caracterización de Unicentro como centro comercial y, por ende, como Lugar para los jóvenes, puedo decir que de acuerdo a los relatos y a la conceptualización teórica, sí representa el modelo planteado de espacio planeado intencionalmente, como un espacio privado grande, "semicerrado", con zonas verdes al aire libre y otras al aire acondicionado, con múltiples ofertas comerciales para distintos tipos de usuarios y con una dinámica de control mediada por el dispositivo de la vigilancia contratada. En ese sentido, Unicentro se plantea aquí no solo como Lugar para los jóvenes, sino para los habitantes de la ciudad en general, que cada vez más encuentran en este tipo de espacios un entorno ideal para habitar. Según el diario la República, especialista en asuntos económicos e industriales, Unicentro junto con Jardín Plaza en Cali, se ubicaron en el top 10 de los centros comerciales que más venden y que más movilización de personas presentaron en todo Colombia. Para 2013, por ejemplo Unicentro vendió más de 350.000 millones de pesos reportados, con un gasto promedio por persona de 98.000 pesos y un tráfico promedio anual de 3,5 millones de personas (La República, 2013). Juan, por su lado, es uno de los grandes motivadores de esas cifras:

\begin{abstract}
Uno de los espacios que más me gusta es la fuente y la terraza de la parte nueva porque es muy fresco y el ambiente es muy bueno, muy tranquilo. A mí gusta ir para hablar, comer, tomar algo o ir a cine; no para 'vitriniar' ni nada de eso: eso solo en diciembre. Yo creo que esos son lugares muy interesantes para ir de conquista o para hablar con amigos: hay condiciones espaciales que permiten ese tipo de relacionamiento.
\end{abstract}

Siguiendo con Guerrero (2014b), la visita al centro comercial está mediada primordialmente por una elección racional basada en el cálculo marcando la integración de los sujetos en el sistema social alrededor del entretenimiento el estilo, que en últimas representan las formas más comunes de apropiación: en torno siempre a la búsqueda de diversión. Aquí la apropiación pasa también por la capacidad de agenciar y transformar el Lugar en esa interacción sujeto-objeto en donde los usuarios también una fuerte agencia para re-significar sus sentidos y usos fundacionales. 
Que un Lugar como Unicentro y otros centros comerciales de Cali estén tomando tanto protagonismo lleva a plantear interrogantes para deliberar sobre cómo va a ser pensada la ciudad por sus ciudadanos y por la planeación municipal: ¿qué pasará con los anteriores Lugares de esparcimiento como los parques o plazas? ¿Acaso se acabarán? ¿Seguirá tendiendo a privatizarse el espacio público para privilegiar la configuración de No-Lugares y de Lugares en formato centro comercial? ¿Será esto el resultado de la prevalencia de un discurso de la seguridad? ¿Cuándo volveremos a salir a la calle?

\section{Conclusiones}

En términos generales, en este artículo me interesaba analizar teórica y reflexivamente las formas de uso o apropiación espacial por parte de los jóvenes en Unicentro y Parque comercial Río Cauca para pensar dichos espacios como Lugares. Así mismo, me interesaba reflexionar si dichas formas de uso o apropiación espacial por parte de estos usuarios están relacionadas con el medio socioeconómico en el que se encuentran situados cada uno de los centros de comercio. Por eso, a partir del análisis teórico de diversos autores respecto a la concepción de Lugar, No-Lugar y Centro Comercial, y a partir de la experiencia etnográfica en cada espacio, puedo optar por presentar tres grandes conclusiones y reflexiones finales al respecto.

En primer lugar, me basé en la concepción de Lugar que lo entiende como un espacio pensado, premeditado y construido intencionalmente, haciendo que aparezca como resultado de un plan estratégico, lo que deja reflexionar en una dinámica de control y vigilancia alrededor de la cual se configura dicha intencionalidad. De igual modo, me pareció importante pensar esta categoría analítica a partir de su dualismo inseparable de su contrario teórico No-Lugar, como la simple negación del Lugar. Igualmente, abrí un espacio de discusión para posibilitar la inclusión de la categoría foucaultiana de heterotopías en el análisis de los Lugares, ante el elemento casi inseparable de vigilancia y control que existe en esta noción.

Como segundo punto, definí un centro comercial como Lugar en tanto que "cumpliera”, teóricamente hablando, con ciertos parámetros básicos en su constitución espacial y urbana: como un entorno grande y privado de la ciudad para ir y ser apropiado, "semicerrado", con zonas verdes al aire libre y otras al aire acondicionado, con múltiples ofertas comerciales para distintos tipos de usuarios y con una dinámica de control mediada por 
el dispositivo de la vigilancia contratada. Así, analicé la llegada de este tipo de Lugar a Cali a principios de los ochenta como el resultado del afán modernizador mediado por un discurso de la seguridad que legitimó su conformación privada y semicerrada, y por la pérdida del protagonismo político, económico y cultural del centro de la ciudad, que provocaría un proceso de fragmentación y concentración urbana del comercio en diferentes nodos de la ciudad: entre ellos, precisamente, el centro comercial.

En ese orden de ideas, como tercer y último punto a rescatar, basándome en los relatos de los jóvenes que me permitieron ingresar por un momento en sus cotidianidades, establecí que los dos espacios comerciales, Parque comercial Río Cauca y Unicentro, se conforman como Lugares condicionados para la consecución de cierto tipo de relacionamiento social y apropiación: aunque el primero no se conformara específicamente como centro comercial debido a sus condiciones espaciales de abandono y falta de gestión y al ingreso de las dinámicas no deseables de los barrios cercanos como la inseguridad y el "desorden".

Por todo esto, sostengo que las formas de apropiación espacial en estos Lugares por parte de los Jóvenes son, para cada espacio comercial, las siguientes:

Parque comercial Río Cauca: En este espacio los jóvenes trasladan las dinámicas barriales sin la necesidad de salir de sus lugares de vivienda, dada la cercanía del Parque comercial con sus barrios. Esto ocurre así debido a que en este espacio pueden hacer lo que quisieran materializar en el barrio, pero que por la inseguridad y el peligro, no pueden siquiera atreverse a intentar. De ese modo, este espacio comercial se convierte en parque, plaza, calle, bar, estanco, cancha de fútbol, un lugar para caminar o simplemente un Lugar para “estar seguros” y disfrutar: por medio, claro está, de la ida al cine o al restaurante a comer, debido al permanente abandono que está acabando con el interés de los jóvenes. Estas formas de apropiación descritas están cercanamente ligadas al contexto en donde se encuentra situado el Parque comercial: zonas excluidas y marginadas.

Unicentro: En este espacio, los jóvenes, que no están interesados en relacionarse a través de dinámicas barriales, buscan romper con su rutina, encontrando en este entorno el Lugar perfecto para 'estar' con demás personas con las que puedan interactuar: dando por sentado la necesidad básica de la seguridad. Esto ocurre así debido a que en este espacio pueden romper con su rutina semanal, por medio del goce y el disfrute a partir de dinámicas de consumo que van desde ir a comer, a tomar o al cine, hasta hablar. Estas formas de apropiación descritas 
también están ligadas al contexto en donde se encuentra situado el centro comercial: en la mitad de unidades residenciales con residentes con alta capacidad adquisitiva y con una lógica similar de encerramiento con condiciones de seguridad que no se ponen en cuestión.

Que los centros comerciales estén tomando cierto protagonismo en Cali lleva a que nos preguntemos por el futuro inmediato y lejano de las formas de vivir, plantear y apropiarnos de la ciudad: ¿será éste un modelo apto solo para el área del corredor de Cali o se extenderá hasta las zonas excluidas de la ciudad como el oriente y la ladera? ¿Cómo se transformarán las formas de apropiación en el futuro de los centros comerciales por parte de los jóvenes y qué harán los pobladores del distrito ante el casi seguro cierre o abandono del Parque comercial? ¿A qué espacios acudirán? ¿Acudirán acaso a Unicentro, a otro centro comercial, o apelarán de nuevo al barrio?

\section{Bibliografía}

ALMARIO, Oscar. (2012). Historia de Cali en el siglo XX. Tomo II. En: E. Morera (coord.), Cali y el Valle del Cauca: configuración moderna y reconfiguración contemporánea de la región y la ciudad-región (pp. 68-91). Cali, Colombia: Universidad del Valle.

CHACÓN, Freddy. (2010). Hábitat-centralidad. Relación determinada por la transformación: Problematización del fenómeno en centralidades conformadas a partir de centros comerciales. En: A. Montaña (ed.), Entretejiendo conceptos: hábitat, centralidad y centros comerciales (pp. 71-120). Bogotá, Colombia: Universidad Nacional de Colombia.

CAMPOS, Fernando y Paulina Yávar. (2007). Lugar, vivienda y urbanidad Urbano. En: Urbano, 10(15), 41-52.

CASTROGIOVANNI, Antonio. (2007). Lugar, no-lugar y entre-lugar: Los ángulos del espacio turístico. En: Estudios y Perspectivas en Turismo, 16(1), 5-23.

CORNEJO, Inés. (2006). El centro comercial desde la comunicación y la cultura. Un modelo analítico para su estudio. En: Convergencia. Revista de Ciencias Sociales, 13(40), 13-37.

DEBORD, Guy. (2003). Comentarios sobre la sociedad del espectáculo. Madrid, España: Anagrama.

FOUCAULT, Michel. (1998). La prosa del mundo. En: E. Frost (ed.), Las palabras y las cosas. Una arqueología de las ciencias humana (pp. 20-35). Madrid, España: Siglo XXI editores. 
Guerrero Caicedo, M. (2014a). Objetos públicos, espacios privados. Usuarios y relaciones sociales en tres centros comerciales de Santiago de Cali. Cali, Colombia: Universidad Icesi.

Guerrero Caicedo, M. (2014b). La articulación de las prácticas sociales a partir de las modalidades de mediación del diseño en el espacio de la Plaza de Cayzedo y la plazoleta del centro comercial Unicentro, en Santiago de Cali. En: Nexus, 12(1), 216-235.

Guerrero Caicedo, M. (2016). Sociología y diseño: pistas, encuentros y des-encuentros. Trans-pasando Fronteras, (9), 11-31. doi:http://dx.doi.org/10.18046/retf.i09.2470

MEDINA, Federico. (1998). El centro comercial: una "burbuja de cristal". En: Estudios sobre las Culturas Contemporáneas, 4(8), 61-91.

MOLINILLO, Sebastián. (2002). Centros comerciales de área urbana: comercialización, gestión y rehabilitación. Madrid: Esic editorial.

MULLER, Jan. (2004). Grandes centros comerciales y recreacionales en Santafé de Bogotá. En: Banco de la República (comp.), Colección de artículos sobre Bogotá. Bogotá, Colombia: Banco de la República.

PRECIADO, Beatriz. (2010). La mansión playboy: la invención del burdel multimedia En: J. Herralde (ed.), Pornotopia: arquitectura y sexualidad en Playboy durante la Guerra Fría (pp. 111-143). Barcelona, España: Editorial Anagrama.

VÁSQUEZ, Édgar. (2001). Cali: tránsito hacia la modernización. En: D. Henao y P. Abella (ed.), Historia de Cali en el siglo 20: sociedad, economía, cultura y espacio (pp. 43-126). Cali, Colombia: Universidad del Valle.

\section{Webibliografia}

GIRALDO, Camilo. (2013). Centros comerciales de Cali tienen clientes más compradores. En: La República. Consultado el 20 de diciembre de 2014, desde http://www.larepublica.co/ consumo/centros-comerciales-de-cali-tienen-clientes-m\%C3\%A1s-compradores_74661

UNICENTRO. (2014). ¿Quiénes somos? En: Unicentro. Consultado el 20 de diciembre de 2014, desde http://www.unicentro.com/contenido/quienes-somos/

URIBE, Hernando. (2012). El Parque Comercial Río Cauca y sus condiciones deplorables. En: Hernando Uribe Castro Blog. Consultado el 20 de diciembre de 2014, desde http:/hernandouribecastro.blogspot.com/2012/10/el-parque-comercialrio-cauca-y-sus.html 